\title{
ARTE E PROCESSOS COLABORATIVOS NA ESFERA PÚBLICA: \\ a experiência do inSITE na região da fronteira entre México-Estados Unidos
}

\begin{abstract}
Luiz Sérgio de Oliveira Doutor em Artes Visuais pela Escola de Belas Artes da UFRJ, Mestre em Artes pela New York University, e Graduado em Artes Plásticas (Pintura) pela Escola de Belas Artes da UFRJ.
\end{abstract}

\section{RESUMO}

Desde sua primeira edição em 1992, o inSITE vem promovendo o espalhamento de projetos de arte nos espaços públicos da região de fronteira entre San Diego (Estados Unidos) e Tijuana (México), tendo atingido a marca de mais de 200 projetos desenvolvidos no contexto da região nas cinco edições da mostra. Neste artigo procuramos investigar o processo de construção do inSITE à luz das novas práticas de arte na esfera pública, evidenciando as contribuições, hesitações e contradições de sua interação com o contexto da fronteira. Procuramos trazer para o debate crítico questões relativas à produção de arte nos espaços públicos na contemporaneidade, tais como a participação das comunidades, o papel e o lugar reservados para o público, os desafios interpostos aos artistas diante de realidades que Ihes são estranhas, além da contínua e tensa negociação entre artistas, curadores e instituições.

Palavras-chave

Arte, colaboração, comunidade, esfera pública

\section{ABSTRACT}

Since 1992 inSITE has promoted the making of art projects across the public spaces of the border zone of San Diego (USA) and Tijuana (Mexico), having commissioned more than 200 projects, conceived by artists for the context of this region. In this article we investigated the inSITE construction process in the light of the new art practices in the public sphere, focusing on the contributions, hesitations and 
contradictions of its interaction with the border context. We aim to bring to the critical debate issues related to the production of art in public spaces today, such as community participation in the production of art, the role reserved for the public, the challenges artists face in attempting to respond to realities that are unfamiliar to them, and the continuous, tense negotiation among artists, curators and institutions.

\section{Keywords}

Art, collaboration, community, public sphere

\section{INTRODUÇÃO}

O globo encolhe para aqueles que o possuem; para os desalojados ou despossuídos, os migrantes ou refugiados, nenhuma distância é mais aterradora que os poucos metros da travessia da fronteira.

--- Homi K. Bhabha, Double Visions ${ }^{1}$

As zonas de fronteira são, por sua própria natureza intrínseca, regiões singulares, demarcadas por encontros de identidades em permanente processo de negociação, espaços de hibridização, de assimilação e resistência. Zonas onde culturas, raças, etnias, políticas, economias e sociedades se tocam, se ouvem, se miram e se contaminam através de um contágio em contínuo aprofundamento e expansão. Em síntese, essa é a realidade das fronteiras, e aquela entre Estados Unidos e México não seria diferente. Uma fronteira que aproxima e aparta dois mundos - o norteamericano e o latino-americano -, na qual, segundo Samuel P. Huntington (1996), se assiste a um choque entre civilizações. Culturas diferenciadas, singularizadas por histórias que cruzaram os séculos em processos de contaminação, consolidação e depuração, e que têm na contemporaneidade apenas mais um momentum na sucessão dos tempos.

\footnotetext{
${ }^{1}$ BHABHA, Homi K. "Double Visions", Artforum International, Nova York, v. 30, n. 5, jan. 1992, p. 88, apud KWON, Miwon. One Place After Another: Site-Specific Art and Locational Identity. Cambridge, Mass.: The MIT Press, 2002, p. 166 (tradução nossa).
} 
É justamente nesse privilegiado canto de mundo, onde se tocam os extremos sudoeste dos Estados Unidos e noroeste dos Estados Unidos Mexicanos, e por extensão, da América Latina, que tem servido como cenário para a instauração e continuidade da mostra internacional de arte na esfera pública inSITE. Um projeto que vem ecoando a própria história da arte pública na contemporaneidade, expandindo-se a partir dos projetos de arte-instalação (1992 e 1994) para se embrenhar pelas especificidades naturais, físicas e políticas da região (1994 e 1997), em uma aproximação cautelosa e gradativa com o contexto e com as comunidades (1997 e 2000), até consolidar-se em um processo de plena colaboração com as comunidades nos chamados community-based projects de 2005. Nesse percurso, o inSITE pareceu repisar caminhos que desde o final dos anos 1960 têm sido experimentados por artistas na busca de alternativas às encruzilhadas do modernismo, atravessando o espaço do espectador, cruzando os muros institucionais dos "museus em ruínas", até se espraiar pela natureza e pelos espaços contaminados das cidades, incorporando (e sendo incorporada) no contexto da cultura do cotidiano; uma arte conversacional em processo dialógico com as comunidades.

Já em 1992, o artista sueco Ulf Rollof ocupou uma área em Playas de Tijuana com o projeto Abandonado II, enquanto dois anos mais tarde, o norte-americano Terry Allen (Cross the Razor / Cruzar la navaja) e a mexicana Helen Escobedo (By the Night Tide / Junto a la marea nocturna) instalaram seus projetos na mesma região, junto ao muro da fronteira (inSITE94). O processo de orientação da arte para o domínio público foi definitivamente consolidado com o inSite_05, cujo projeto curatorial apontava para a realização de projetos em estreita colaboração com as comunidades.

Uma das mais melhores propriedades do inSITE é o caráter francamente temporário, quando não efêmero, transitório e absolutamente desmaterializado de seus projetos. Dessa maneira, tem sido evitada a ocupação permanente dos espaços públicos, em situações que, de uma maneira ou de outra, independentemente das intenções, carregam certa marca do autoritarismo, representado pela apropriação dos espaços públicos. Conforme apontado pela historiadora da arte Patricia C. Phillips, a "arte pública efêmera [evita] a paralisação requerida para expressar valores eternos para um audiência ampliada com 
diferentes formações e frequentemente com diferentes imaginações verbais e visuais" (1999, p. 303, tradução nossa).

Os projetos do inSITE não se configuraram com uma ocupação duradoura dos espaços públicos, podendo ser apontados como exceção o citado Abandonado I/ de Ulf Rollof, o qual por vias mais que oblíquas ainda permanece parcialmente presente em Playas de Tijuana².

Em um cenário "altamente carregado, politizado e contencioso" (FIRSTENBERG, 2005, p. 60, tradução nossa), propício para a emergência da arte articulada na interseção com a política na esfera pública, em processos comprometidos com mecanismos de disseminação da arte nos meandros da cultura do cotidiano, o inSITE se configura como um coerente produto cultural dessa mesma região, atravessado pelo embate de diferentes interesses e extraordinárias injunções das forças políticas regionais, as quais, por sua vez, acabam por ajudar a formatar a mostra, por influenciar seus objetivos, direcionar suas metas e consagrar suas limitações.

Dessa maneira, as implicações - culturais, políticas, sociais, econômicas - dessa região conflituosa, que se constituem na matéria prima a ser investigada, interpretada e reinventada pelos artistas convidados a desenvolver seus projetos de arte na região, estiveram desde sempre incrustadas na própria estrutura do inSITE, criando uma tensa dialética entre o consentir que os mecanismos de controle dessas forças políticas viessem a formatar a mostra, e o resistir, empregando os próprios recursos e canais criados e providos pela mostra para evidenciar a ação e a coerção exercida pelos interesses locais.

\section{A FRONTEIRA DE CRISTAL}

O contrato de serviços explicitava-o: virão do México para Nova York, às sextas-feiras à noite, para trabalhar nos sábados e domingos, voltando para a Cidade do México nos domingos à noite.

\footnotetext{
${ }^{2}$ Referência à visita realizada em setembro de 2005.
} 
- Com as passagens de avião e tudo sai mais barato do que contratar trabalhadores aqui em Manhattan. Poupamos entre 25 e 30\% - explicaramIhe os seus sócios gringos.

--- Carlos Fuentes, $A$ fronteira de cristal $\left.\right|^{3}$

Lisandro Chávez, mexicano, prestador de serviços de limpeza de prédios comerciais $\mathrm{Na}$ ilha de Manhattan, e Audrey, jovem e talentosa executiva norte-americana, ela espelhando sua individualidade, um dos mitos mais caros à sociedade norteamericana - YERDUA / AUDREY -, ele simplesmente um NACIXEM, são os personagens centrais do formidável conto de Carlos Fuentes $-A$ fronteira de cristal - que se encontram no $40^{\circ}$ andar do edifício de escritórios da Park Avenue, no coração chique da cidade de Nova York. Metáfora das ambiguidades que marcam o fascínio e a concomitante rejeição entre mexicanos e norte-americanos, uns sobre os outros, encantamento pelo que vêem nos outros e sabem que não são, que se reconhecem incapazes de ser; uma sedução que contracena com preconceitos que os antagonizam e apartam. Ele, um trabalhador não-qualificado; ela, uma executiva que explora seu talento e seus melhores haveres intelectuais, sendo retribuída à altura. Ela a exportar criatividade e competência para o mundo, ele alugando seus braços para o irmão rico do norte, que Ihe oferece uma remuneração inimaginável na realidade da economia mexicana.

Dois lados de uma fronteira multifacetada de uma região que resiste em perceber a si mesma como binacional. Nessa fronteira se entrechocam imaginários, percepções de mundo, realidades. Ao sul, a enorme diversidade e riqueza de uma América Latina que peleja por desvencilhar-se de séculos de exploração. Do lado de cima dessa linha imaginária, o país mais rico e mais poderoso do planeta, capaz de utilizar sua máquina de guerra em defesa de seus interesses políticos e comerciais, em defesa do interesse da nação que, como poucas, tem a compreensão de que para defender seu bem-estar, se preciso for, vai-se à guerra. Uma nação que foi constituída sob a égide do enfrentamento, das guerras e conquistas. Um país que, como o próprio México, se constituiu territorialmente através de contendas no

\footnotetext{
${ }^{3}$ FUENTES, Carlos. "A fronteira de cristal". In: A fronteira de cristal. Trad. Mauro Gama. Rio de Janeiro: Rocco, 1999, p. 163.
} 
enfrentamento com os nativos da América do Norte, e que por fim se confrontaram em guerra em meados do século XIX.

A fronteira de cristal revela não apenas os personagens de uma realidade culturalmente rica, por vezes trágica, sombria e melancólica. Uma fronteira de cristal, uma linha que insiste em ser linha nos mapas da geopolítica, que insiste em demarcar territórios de soberania, poder e exclusão, que parece empenhada em remover as possibilidades de integração, mantendo as partes sulcadas.

Mas essa é uma linha que está longe de ser verdadeiramente uma linha; evidenciase como uma linha que se alarga, que ganha territorialidade, que se estende por planícies e vales dos dois lados da fronteira. Embora se apresente como barreira com função específica, não impede que as partes se vejam, não obstrui a sedução entre os dois lados. A sedução do olhar que viaja, que atravessa as barreiras dos ditames da geopolítica, alargando a linha de fronteira, a qual deixa de ser um fio no velho atlas de geografia para se transformar em região de fronteira, domínio híbrido caracterizado pelo entrecruzamento de percepções de mundo calcadas em tradições distintas, pertencentes a tempos pretéritos que se manifestam em uma extraordinária produção de arte e de culturas, tornando as regiões de fronteira em territórios de enorme riqueza e diversidade cultural. Regiões que se encaixam na categoria de heterotopia, conforme elaborada por Michel Foucault, como um tipo de espaço que é um contraespaço, um lugar fora de todos os lugares:

Acredito que entre as utopias e esses outros lugares, essas heterotopias, exista um tipo de experiência difusa e deslocada, que poderia ser o espelho. O espelho é, afinal de contas, uma utopia, na medida em que é um lugar sem lugar. No espelho eu me vejo lá onde não estou, em um espaço virtual, imaginário que se abre por trás da superfície; estou lá, lá onde não estou, uma espécie de sombra que me dá minha própria visibilidade, que permite que eu me veja lá onde inexisto: essa é a utopia do espelho. Mas ele é também uma heterotopia, já que o espelho em realidade existe, exercendo um tipo de contra-ação à posição que eu ocupo. Do ponto de vista do espelho, eu descubro minha ausência do lugar onde estou, já que nele eu me vejo. (1986, p. 24, tradução nossa) 
Muito antes da chegada dos europeus do lá de cá do Atlântico, as terras americanas eram ocupadas por diferentes povos com formas de organização singulares, maneiras distintas de se relacionar com a vida, com a morte, com a natureza, com o passado e o futuro. A América que antecedeu a Cristóvão Colombo era ocupada ao norte por nações nômades e guerreiras, dedicadas à caça, bem dessemelhantes daquelas instaladas em torno da atual América Central, que desenvolveram atividades agrícolas e puderam estabelecer civilizações baseadas no sedentarismo, com "complexas instituições sociais e políticas, dominadas por teocracias guerreiras que inventaram rituais refinados e cruéis, uma grande arte e vastas cosmogonias inspiradas por uma visão muito original do tempo" (PAZ, 1984, p. 184).

São elementos de distinção que deixariam seu legado no desenvolvimento ulterior dos Estados Unidos e do México, já a partir dos primórdios da colonização, determinando mesmo as políticas que ingleses e espanhóis destinaram às colônias, uma vez que a "política espanhola de submissão e de conversão não poderia ter sido aplicada às belicosas nações indígenas do norte com a mesma facilidade com que se aplicou às populações da América Central" (PAZ, 1984, p. 187).

Ao lado das distinções que apartavam os habitantes da América pré-colombiana, e que se refletiam nos diferentes níveis de complexidade das estruturas organizacionais das civilizações, se sobrepuseram as diferenças entre espanhóis e ingleses, tão intensas como aquelas que distinguiam as nações nativas entre nômades e sedentárias. As nações norte-americana e mexicana foram forjadas nesse amálgama de adições que as enraízam em universos paralelos, traços que colocam de um lado um dos países-símbolo da modernidade do século $X X$ e do outro, uma nação (ou conjunto de nações que se alinham até a Terra do Fogo no sul da América do Sul); nações que se distinguem no direcionamento de seus olhares e perspectivas, apontados em direções contravertidas: enquanto uma tenta antecipar o futuro, a outra não se desprende de um passado glorioso, porém arrasado e ainda não devidamente resgatado, um México de passados que se sobrepõem. 


\section{AS FRONTEIRAS DA ARTE}

O reconhecimento da relevância da situação e do processo de interação comunitária tem permeado a produção de arte no domínio público desde o final da década de 1980, quando a polêmica remoção da obra Tilted Arc, escultura do norte-americano Richard Serra, expôs a fragilidade da argumentação em prol da permanência da obra no espaço público na especificidade e perenidade do site. Desde então, as articulações da arte no domínio público têm apontado para outro norte, informadas por idéias situacionistas em torno da política do cotidiano, sua dinâmica, transitoriedade e fluidez, fazendo como que o "nosso entendimento de site mudasse de uma locação física, fixa, para algum lugar ou algo constituído através de processos sociais, econômicos, culturais e políticos" (KWON, 2002, p. 10, apud DOHERTY, 2004, p. 10, tradução nossa).

Nesse contexto histórico que patenteou a imprecisão e inadequação do termo sitespecific para lidar com as novas práticas da arte em diálogo com as comunidades, percebidas como arquitetas do cotidiano, o glossário da arte foi inundado por novos termos que enfatizavam o processo de interação comunitária em práticas de arte socialmente engajadas; como se fosse algo inevitável desde que os artistas, ainda no final dos anos 1960, abandonaram o reduto tradicional da arte nos espaços das galerias de arte e museus em favor dos espaços da natureza, esparramando-se por diferentes paisagens naturais e comprometendo-se com a cultura do cotidiano.

Os projetos de interação com as comunidades se caracterizam pela desconstrução das práticas tradicionais de criação da arte, obrigando os artistas a empreender um processo de colaboração que redimensiona, amplia e subverte a lógica de organização do trabalho, suprimindo resquícios da autonomia modernista, da qual o isolamento do artista era reflexo e parte constitutiva. Além disso, ao borrar em um mesmo eixo central as esferas distintas da produção e da circulação da arte, esses projetos tentam superar a fratura político-ideológica entre intenção (produção) e apreensão (circulação.

No entanto, o mais significativo é que esses projetos implicam na realocação de um tipo de público que havia sido negligenciado pela arte modernista, sendo reinserido no núcleo central do processo criativo, deixando de ser uma periferia relegada a uma situação de lateralidade, uma não-situação, para se transformar na raison d'être 
do processo de criação. É certo que esse processo precisa ser ressignificado como um movimento de abertura, ao invés de ser percebida como a substituição de uma exclusão por outra. Em outras palavras, é importante que os projetos de articulação, interação e colaboração com as comunidades suscitem questões e reflexões substantivas não somente para aquela comunidade diretamente banhada pelo projeto, mas que sejam substancialmente relevantes para outros universos comunitários, sem que se fechem em situações que de tão específicas se tornem excludentes.

Além disso, e nesse ponto talvez resida o maior desafio para os projetos de arte socialmente engajados, é imprescindível superar o sentimento de explotação tanto por parte das comunidades quanto por parte dos artistas, permitindo que as relações e desdobramentos desses projetos sejam pautados em uma ética que necessita encontrar seus termos, evitando-se os riscos da beneficência arrogante, da insensibilidade, da superidentificação e da exploração pura e simples das situações comunitárias, independentemente se carentes ou abastadas, para fins exclusivos de reinserção do projeto no sistema tradicional de arte.

No entanto, esse cenário de imbricação com as comunidades parece ganhar em dificuldade quando envolve artistas vindos de regiões distantes daquelas das comunidades, apresentando-se em situações inusitadas para esses artistas, demandando estratégias que propiciem um melhor entendimento e um maior comprometimento com esses contextos a desafiar seu processo criativo. E esse tem sido um fenômeno muito presente na contemporaneidade, com os artistas itinerando pelo mundo em resposta a convites de bienais e mostras internacionais para que desenvolvam projetos específicos em situações que se Ihes apresentam. Nessas novas práticas da arte, o artista ganha mobilidade, deixando claro que agora quem viaja é o artista, não mais a obra; um artista que viaja para prestar um serviço de arte, através da criação de um evento, uma performance, um projeto, eventualmente uma obra, que por sua vez permanecerá vinculada àquela realidade em que foi gerada, na memória que seja, depois da partida do artista.

Esse "artista itinerante, [...] não mais um criador de objetos atado a um ateliê, trabalhando agora essencialmente sob demanda" (KWON, 2002, p. 46, tradução nossa), precisará de muita cautela e perspicácia para simplesmente não naufragar 
nas facilidades e armadilhas dos contextos apresentados. A começar pela própria maneira como essa apresentação se dá. Em algumas situações, como é o caso do inSITE, programas de residência têm sido criados com o objetivo de subsidiar uma melhor resposta desses "artistas itinerantes", expondo-os a estímulos que possam (re)emergir transmutados em seus projetos e criações de arte. No entanto, essa mediação da instituição é plena de riscos, podendo acarretar em respostas previsíveis, e mais que isso, em respostas estimuladas e esperadas por essas instituições.

Miwon Kwon lembra que "a interação entre o artista e um determinado grupo comunitário não é baseada em uma relação não-mediada. Ao contrário, está circunscrita dentro de uma complexa rede de motivações, expectativas e projeções entre todos os envolvidos" (KWON, 2002, p. 141, tradução nossa). Portanto, o artista, ao deixar seu ateliê-bolha, abandona seu isolamento, tornando-se permeável a essa "complexa rede de motivações, expectativas e projeções", sendo necessário atenção para evitar a instrumentalização da arte e sua redução por ansiedades e interesses alheios.

Essa é uma conjuntura de riscos. Enquanto os objetos de arte, criados pelos artistas a partir de seus ateliês circulavam por diferentes situações e universos, abrigados pelas instituições de arte e involucrados em sua autonomia, tanto uns quanto outros - artistas e obras de arte - pareciam protegidos. Nessa nova situação, o artista - e não a obra - fica exposto aos riscos e armadilhas da incompreensão, da superficialidade e simplificação, da manipulação e do equívoco.

\section{inSite_05: PROJETOS DE ARTE NA REGIÃO DA FRONTEIRA}

Organizado em torno dos projetos desenvolvidos em interação com as comunidades, o inSite_ $05^{4}$ reverberou práticas que há mais de duas década povoam o cenário contemporâneo de arte, no qual os artistas têm se aproximado de diferentes comunidades e contextos na expectativa de interação e colaboração na criação e desenvolvimento de projetos artísticos.

\footnotetext{
${ }^{4}$ A edição de 2005 do inSITE foi apresentada pela direção da mostra com esta grafia: inSite_05.
} 
Embora a literatura crítica da arte contemporânea tenha produzido reflexões significativas a respeito da compreensão e formatação das comunidades com as quais os processos de arte têm procurado sua imbricação, o universo curatorial do inSite_05 pareceu instaurar-se distante de preocupações que buscassem ou que sinalizassem uma definição, funcional que fosse, de "comunidade", que consubstanciasse o interesse da curadoria em projetos desenvolvidos em interação com as comunidades na edição de 2005 da mostra.

De qualquer maneira, as comunidades, em suas concepções mais fechadas, têm sido designadas "como um grupo de pessoas identificadas com cada uma por um conjunto de interesses e formações comuns" (KWON, 2002, p. 145, tradução nossa), "como sujeitos idênticos em comunhão através do mútuo reconhecimento de uma essência partilhada" (KESTER, 2004, p. 154, tradução nossa), ou ainda como "um desejo de seres que são transparentes uns para os outros, relações de identificação mútua, aconchego e conforto sociais" (Iris Marrion Young apud KWON, 2002, p. 149, tradução nossa). Essas definições apontam para a aproximação de idênticos e para o estabelecimento da unidade de semelhantes, com a consequente exclusão da diferença. Algo que Grant H. Kester denominou de "coletivo fascista", e que parece desconhecer a impermanência, o contínuo e acelerado processo de desconstrução e reconstrução das identidades nos tempos pós-modernos, em que a cristalização de uma identidade somente será possível através de um violento processo de redução das complexidades identitárias.

A opção do inSite_05 em não se embrenhar por esse debate em torno da constituição conceitual das comunidades propiciou a possibilidade de interação com diferentes tipos de "comunidade", desde algumas extremamente fechadas (como a colônia militar de Murphy Canyon, San Diego, no projeto de Althea Thauberger ou os pacientes psiquiátricos do Centro de Salud Mental del Estado de Baja Califórnia, Mexicali, no projeto de Javier Téllez) enquanto outras, em função de sua impermanência e não identificação, pareciam se configurar como uma virtualidade, como são os casos dos "migrantes que cruzam a fronteira dos Estados Unidos e México todos os dias" 5 , no projeto de Judi Werthein, ou dos passantes da Puente

\footnotetext{
${ }^{5}$ Conforme informação na brochura do projeto de Judi Werthein - Brinco -, publicado pelo inSITE.
} 
México, Tijuana, deixando como contribuição e elos seus prenomes estampados no projeto de Felipe Barbosa e Rosana Ricalde.

Articulado em torno de um eixo que relegava a materialidade da interação com a comunidade a uma condição de absoluta lateralidade e desnecessidade, o inSite_05 privilegiou práticas de arte comprometidas com a efemeridade: "geralmente orientada para o processo ou para a performance, esta arte pública busca (re)pensar modelos de identidade de grupo e sua representação pública" ${ }^{6}$. Essa desconstrução de expectativas teria como aspecto positivo liberar os artistas do compromisso da geração de resíduos artísticos que justificassem o alto investimento da mostra.

Por outro lado, a impermanência dos projetos do inSite_05, em que muitos se configurariam como eventos únicos, indubitavelmente dificultaria o processo de acompanhamento pelo público. A ênfase na interação comunitária, dialogando na volatilidade do processo de gestos fugidios condenados ao desaparecimento, empurrou o inSite_05 para um "não-sei-onde", para um não-lugar, uma dispersão territorial dos projetos de arte "derramados" por localidades distintas e distantes das cidades de San Diego e Tijuana, acentuada pela esgarçadura da cartografia da região, que comporta duas cidades altamente espalhadas, o que é agravado pelas restrições no fluxo através da fronteira no sentido sul-norte.

É bem verdade que com ou sem qualquer remanescente objetual, a aderência do inSite_05 às comunidades interagidas representou uma clara definição dessas comunidades como seu público, na qual o projeto ia sendo absorvido e consumido enquanto se desenvolvia, sendo usufruído pela própria comunidade coautora no próprio ato da criação. Esse processo de definição da comunidade aderida ao projeto como sendo igualmente seu público privilegiado, e eventualmente o único que de fato importaria, empurrou o "público secundário" (DOHERTY, 2004, p. 9) para uma zona de alienação, abandonado à própria sorte.

A insistência da curadoria em estabelecer conexões com a comunidade revelava 0 desejo da criação de uma mostra que aderisse às práticas de colaboração e coparticipação que têm sido realçadas na produção de arte no domínio público, herdeiras do "que se chamava de vanguarda" que reaparecem na produção da arte

\footnotetext{
${ }^{6}$ Bypass, material de divulgação da mostra inSite_05
} 
"reformatadas com base em diferentes pressupostos filosóficos, culturais e sociais, [...] propondo novos modelos perceptivos, experimentais, críticos e participatórios", mesmo que tenha deixado de ser "apresentada como um fenômeno precursor de uma inevitável evolução histórica" (BOURRIAUD, 2002 [1998], p. 12-13, tradução nossa). Essa adesão a práticas que ainda preservam certo acento e gosto das práticas de vanguarda é consistente com o anseio e a pretensão da direção do inSITE em buscar a inserção e consolidação da mostra no mainstream da produção de arte contemporânea.

Mas ao nos aproximarmos da comunidade com intenção de arte, o que estaríamos efetivamente buscando? Interessante notar que a prática de arte do inSite_05, ao avançar em direções levemente esboçadas nos pressupostos da curadoria, revelou uma consistente aproximação com o "ativismo conciliatório" que tem permeado parte significativa da arte contemporânea, em oposição aos excessos da produção orientada para o mercado da década de 1980: "muitos viram a necessidade de um renascimento moral, [sendo] a justiça promovida como novo valor estético supremo, [consignando à arte um] valor meramente instrumental [...] sendo tão boa quanto o peso de seus benefícios sociais". (JUSIDMAN, 1995, p. 46, tradução nossa)

Vários projetos do inSite_05 parecem ter se articulado por entre os resquícios dos "traços redentores" da arte (KRAVAGNA, 1998, p. 4), seguindo paradigma defendido pela curadora norte-americana Mary Jane Jacob na mostra Culture in Action (1993), que propunha um redefinição do papel da arte pública, a qual abandonaria a perspectiva de "renovar o ambiente físico para melhorar a sociedade, [deixaria] de promover a qualidade estética para contribuir para a melhoria da qualidade de vida, [desistiria] de enriquecer as vidas para salvar vidas". (JACOB, 1995, p.56, tradução nossa)

Independentemente do quão se dê de crédito às quimeras da arte diante dos males que afligem o cotidiano das sociedades contemporâneas, ou do fato de que, em momento algum, essa crença replicou explicitamente ou foi reconhecida abertamente na retórica propositiva do inSite_05, percebemos que a articulação com as comunidades em alguns dos projetos de arte ultrapassou as expectativas da curadoria, instaurando-se no plano próximo do assistencialismo, ampliando o escopo dos "serviços artísticos" delineados por Andrea Fraser (2005). 
Para adensar nossas reflexões em torno das práticas de arte desenvolvidas em colaboração com as comunidades, promovidas em consonância ao projeto do inSite_05, elegemos três projetos desenvolvidos pelos artistas Paul Ramírez Jonas, João Louro e Judi Werthein, as quais a seguir nos dedicaremos.

\section{A boa-fé de Paul Ramírez Jonas}

Final de tarde de 23 de agosto de 2005, Balboa Park. No Centro Cultural de la Raza, Paul Ramírez Jonas dava início ao inSite_05 com sua palestra-performance Su casa, mi casa, "um exercício de confiança entre estranhos, [...] um diálogo sobre reciprocidade e fé, [...] uma estrutura simbólica para as interconexões e cumplicidade entre espaços e indivíduos nesta região de fronteira"7.

Naquela tarde, não mais que 15 pessoas se reuniram no Centro Cultural de la Raza para assistir a primeira performance de uma série de dez de Paul Ramírez Jonas espalhadas pelos dois lados da fronteira. Um encontro singelo, quase íntimo, no qual o artista discorreu sobre as possibilidades e restrições de acesso, sobre o diálogo entre os espaços públicos e privados, "sobre as fronteiras entre tua casa e a rua", uma maneira fantasiosa, sutil, de tratar grandes temas como a questão da fronteira ${ }^{8}$. Ao final do encontro, o artista convidava os presentes para que trocassem cópias de suas chaves, em uma demonstração inequívoca de confiança no "outro", recorrendo ao auxílio de um profissional e de uma máquina presentes em cena.

\footnotetext{
${ }^{7}$ Texto de Tania Ragasol, curador assistente do Interventions, publicado na brochura do projeto de Paul Ramírez Jonas para o inSite_05.

${ }^{8}$ Conforme manifesto pelo artista em entrevista com o autor em San Diego, Califórnia, na manhã do dia 29 de setembro de 2005. Outras citações da entrevista nesta parte do artigo aparecerão simplesmente entre aspas.
} 


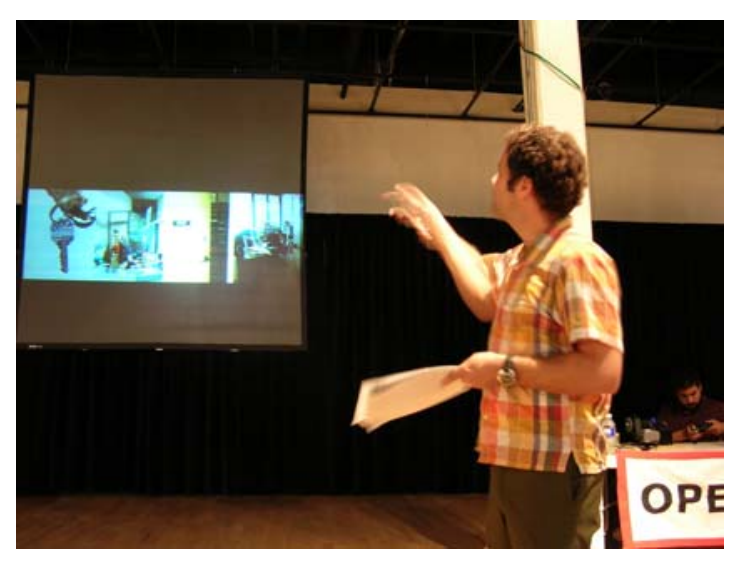

Paul Ramírez Jonas

Su casa, mi casa, 2005.

Centro Cultural de la Raza, San Diego

Foto do autor

A questão central para o artista girava em torno das audiências, fundamental para a produção de arte na contemporaneidade, em especial para aquela vertente que se autodenomina "pública". Não foi por outro motivo que Paul Ramírez Jonas (Pomona, Califórnia, 1965) decidiu apresentar sua performance em dez diferentes localidades espalhadas pela região da fronteira: Tijuana, Imperial Beach, San Diego e La Jolla.

O próprio formato dessas performances - palestras com diapositivos que nos remetem às aulas de história da arte - estabelecia uma perfeita demarcação dos territórios opostos do artista e do público, colocando-os frente a frente e criando uma oportunidade singular para que o artista se expusesse às respostas de diferentes plateias/comunidades, alternando entre estudantes universitários de arte, história da arte, arquitetura e design, crianças sob amparo do Estado nos centros de proteção à infância, e internos penitenciários de Tijuana - "uma audiência involuntária, que já está lá; [...] como não poderiam gostar? Eles não têm nada para fazer, são prisioneiros, e foram duas horas de entretenimento", afirmou o artista entre risos astuciosos.

Ao contrário de outros projetos de arte do inSite_05 que pareciam sugerir a partilha da autoria da obra, enfatizando o processo de colaboração com a comunidade envolvida, transformada a um só tempo em coautora e audiência privilegiada, Su casa, mi casa preserva o lugar de criação para o artista, reservando à comunidade o papel de participante: "não penso que minha obra estabeleça uma 'colaboração' com a comunidade; acredito que ela admita a 'participação', o que é muito diferente", 
afirma o artista, receoso de ser mal interpretado e entendido como reacionário, acrescentando que as pessoas não querem fazer a obra de arte com o artista, que "as pessoas estão interessadas naquilo que o artista tem a oferecer, e reagem a idéia de colaboração com a comunidade: 'agora eu também tenho que fazer a obra de arte?"', provoca Paul Ramírez Jonas entre novos risos.

Mas que comunidade é essa, ou melhor, que comunidades são essas com as quais o projeto Su casa, mi casa interagiu, em um processo que não ultrapassaria os limites da participação, conforme notado pelo artista? Ao contrário de outros projetos do inSite_05 em que a imbricação com a comunidade borrou os limites entre artista e comunidade, criador e público, tempo da criação e tempo da apresentação, em Su casa, mi casa há uma clara distinção entre essas diferentes categorias, como que a consolidar as fronteiras territoriais evidenciadas na performance. Da mesma maneira, as dez apresentações da performance ocorreram para dez comunidades diferentes.

Nesse sentido, ao distinguir o momento da criação daquele da apresentação da performance, o projeto de Paul Ramírez Jonas parece reverberar os dois tipos de comunidade apontados por Grant H. Kester, que opõe as "comunidades préexistentes, politicamente coerentes" àquelas que são "criadas pelos artistasrepresentantes para a completude de um projeto de arte" (KWON, 2002, p. 145, tradução nossa). Enquanto as apresentações do artista foram realizadas para distintas comunidades mais ou menos fechadas, mais ou menos coerentes, tais como os universitários agrupados por interesses comuns, presidiários reclusos no cumprimento de suas penas, ou crianças carentes sob o amparo do Estado, a interação no plano da criação se deu como diferentes indivíduos e personalidades que, para além de suas singularidades, se aproximaram para emprestar suas histórias acerca de suas territorialidades, para ilustrar a palestra de Paul Ramírez Jonas, passando a integrar uma comunidade extremamente precária que se reúne apenas na sucessão de imagens diapositivas da obra de Ramírez Jonas, uma comunidade marcada, acima de tudo, pela diferença, momentamente suspensa na participação de Su casa, mi casa.

Paul Ramírez Jonas reagiu à interação proposta pela direção da mostra com os interlocutores no processo de definição e formatação dos projetos, o que, segundo o 
artista, "se transformou em uma disputa em que os curadores-críticos atacavam e os artistas se defendiam; uma tortura". Interessante notar que no processo de acompanhamento dos projetos de arte do inSite_05 por parte da curadoria, a confiança, algo tão caro a Paul Ramírez Jonas em sua performance, parece ter se transformado em "moeda podre"; afinal, mesmo depois de formalmente convidados a participar da mostra, os artistas tiveram que passar por repetidas sessões de apresentação, defesa e aprovação.

O projeto Su casa, mi casa, de Paul Ramírez Jonas, evidenciou sua potência justamente por sua singeleza e desespetacularização, pelo uso de recursos audiovisuais que pareciam há muito descartados como defasados pelos artistas contemporâneos - inserindo o projeto na contramão de uma corrida tecnológica -, pelo seu espalhamento dos dois lados da fronteira, e principalmente por se oferecer docemente a diferentes comunidades.

\section{O ouro de João Louro}

A estrutura ziguezagueante do projeto de João Louro para o inSite_05 - The Jewel / In God We Trust - reflete com justeza o impacto da primeira visita do artista à região, circulando entre a riqueza aparente de San Diego e a miséria evidente de Tijuana, mesmo que saibamos o quanto essas situações estão entrelaçadas.

O projeto tem como ponto de partida a busca e a compra de um carro europeu de luxo - no caso, um Jaguar - em um dos inúmeros cemitérios de automóveis de Tijuana, para onde são levados depois de consumidos por inteiro nas vias e supervias da Califórnia. O Jaguar escolhido e comprado pelo artista para seu projeto, um carro-sucata - sem rodas, amassado, enferrujado, etc. - passaria então por um processo de transformação ainda em Tijuana, sendo transmutado, como que por ação do rei Midas, em uma "jóia" - The Jewel -, recoberto com folhas de ouro antes de ser transportado de volta a San Diego para uma exposição de 4 horas na concessionária Ferrari e Masserati de San Diego na "jóia do Pacífico", e um leilão na residência de Eloisa Haudenschild, presidente do conselho do inSITE, também em La Jolla. 

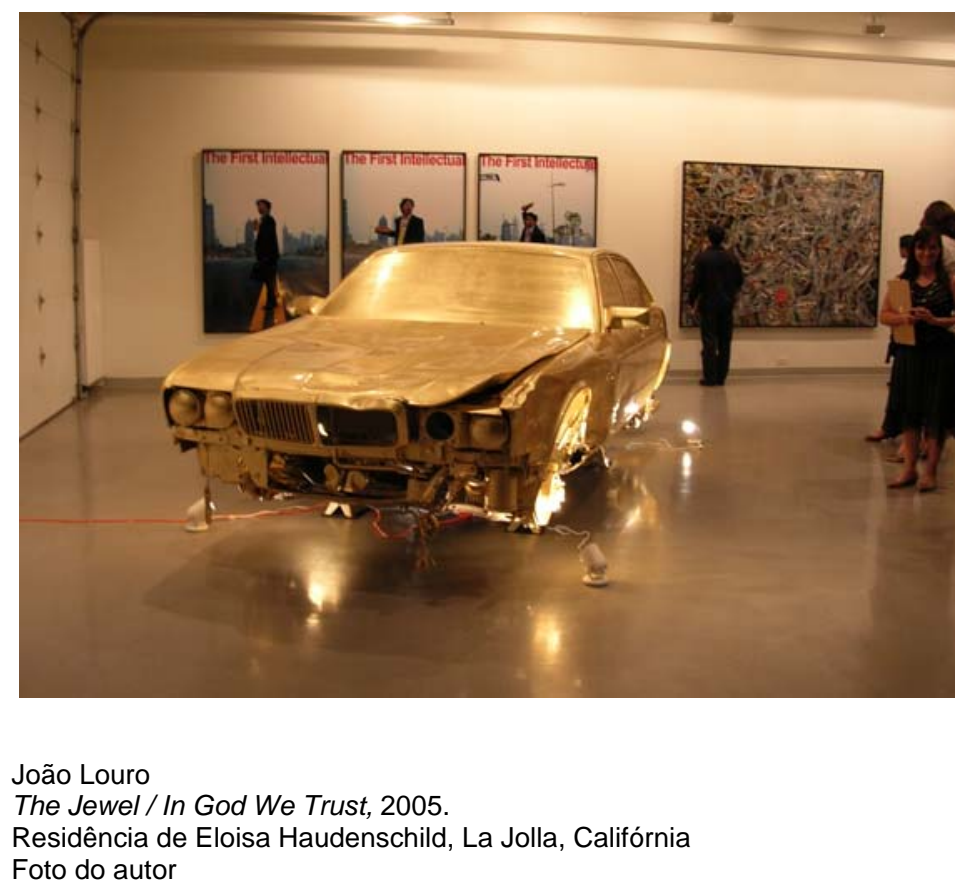

Mas todos esses eventos, essas idas e vindas, não significam a conclusão do projeto de João Louro. Os recursos da venda do carro-transformado-em-jóia-de-arte seriam enviados para crianças da Escola El Principito, de Tijuana ${ }^{9}$, depois de trocados por notas de um dólar, "a nota simbólica norte-americana, para que nas notas as crianças fizessem um 'exercício visual'" e remetê-las de volta à circulação, em um projeto claramente devedor das "inserções em circuitos ideológicos", 1970, do brasileiro Cildo Meireles, conforme descrito pelo artista:

As crianças vão poder enviá-las ou trocá-las no banco, ou enviar esses desenhos (que no fundo são as notas) por correio para quem elas quiserem. Há uma lista de pessoas que eles gostariam de enviar esse dinheiro. E o que parece curioso, já dentro do espírito do inSite[05] é que o próprio projeto, o meu projeto, também não vai terminar nesse momento; porque, suponho eu, que algum dinheiro entrará em circulação novamente, e um dia que se vá tomar um café, pode-se receber de troco um desenho de uma criança de Tijuana que não pôde passar na fronteira... O projeto, no fundo, [diante] desta circularidade econômica, não vai parar, ele vai se prolongar no tempo em pequenas obras de arte, pequenos desenhos a

\footnotetext{
${ }^{9}$ Conforme informação do artista em entrevista com o autor na manhã do dia 26 de agosto de 2005 no hall do Manor Park Hotel em San Diego. A partir deste ponto, as citações da entrevista de João Louro com o autor serão apresentadas simplesmente entre aspas.
} 
circular, [desenhos] que têm valor, que é de um dólar, de crianças que não puderam atravessar a fronteira para ir ao museu, por exemplo.

O que o artista identifica como o "espírito do inSite_05" é justamente a ênfase na colaboração e no caráter processual do projeto, não necessariamente aquilo que identificamos como uma dificuldade do artista em encontrar um melhor balizamento no tempo (e no espaço) para seu projeto, sem se alongar em desdobramentos sem fim. É verdade que a ênfase no processo de colaboração em alguns casos do inSite_05 estendeu a duração das obras e a repercussão desses projetos em uma sobrevida para além (anterior ou posterior) de suas aparições mais públicas, para além do que era trazido ao conhecimento direto de um público eventualmente ampliado..

No entanto, em alguns casos, os artistas parecem ter perdido seu melhor timing, encompridando seus projetos para além do razoável, subtraindo-Ihes intensidade e veemência, como a revelar uma eventual dificuldade em concluir suas próprias obras. Nesse particular, acreditamos que João Louro tenha revelado certa dificuldade em acrescentar ao seu projeto o desejável ponto final.

Apesar dessas objeções, The Jewel - In God We Trust se insere nos debates correntes no plano institucional da arte, ao suscitar questões referentes às relações de poder que dominam o sistema de arte. Afinal, quem teria o "toque de Midas", a capacidade para transformar "lixo em luxo"? O artista? A instituição inSITE? Para além do comentário irônico que identifica a arte como luxo, o projeto de Louro parece - mais uma vez - recuperar o gesto inaugural de Marcel Duchamp. Mesmo que, ao contrário da crença de Louro que reserva o "toque que transforma tudo em ouro" ao artista, o resultado do leilão do Jaguar-transformado-em-jóia ficou muito aquém das expectativas mais modestas, cobrindo com alguma dificuldade os custos daquela etapa do projeto, demolindo qualquer ilusão quanto à centralidade do artista no processo, evidenciando - mais uma vez - quem tem o poder de transformar "lixo em luxo". 


\section{Os sonhos descalços de Judi Werthein}

O projeto de Judi Werthein para o inSite_05 - Brinco ${ }^{10}$ - girou em torno do desenvolvimento, fabricação e distribuição de um tênis, produzido com "informações e materiais que são relevantes e que podem ajudar àqueles que ilegalmente cruzam a fronteira" ${ }^{\prime 1}$.

Configurando-se como o projeto mais político da edição de 2005 do inSITE, Brinco foi desenvolvido a partir de uma pesquisa da artista na região, que incluiu contatos com organizações de apoio aos migrantes e com os próprios migrantes, além da travessia da fronteira pela artista, percorrendo os caminhos da ilegalidade. Nesse contexto de caminhadas e observações, Judi Werthein pôde listar algumas necessidades por vezes vitais para esses migrantes, de maneira a incluí-las como pequenos apetrechos agregados ao par de tênis: um mapa da região impresso na palmilha e na sola interna do calçado, uma pequena lanterna, uma bússola, um pequeno bolso para a guarda de algum dinheiro para a travessia e os primeiros momentos que se seguiriam, além de ícones da fé popular a iluminar o trajeto: na biqueira, a águia, emblema nacional norte-americano, e um pequeno retrato do padre mexicano Toribio Romo, guardião dos imigrantes ilegais ${ }^{12}$, na parte posterior do tênis.

10 "Brinco" é o termo utilizado pelos mexicanos da fronteira para designar a travessia ilegal para os Estados Unidos.

${ }^{11}$ Conforme relato de Judi Werthein em entrevista com o autor na manhã do dia 29 de agosto de 2005, no Jimmy Carter's Café, San Diego, Califórnia. Neste trecho do artigo, outras citações dessa entrevista aparecerão simplesmente entre aspas.

12 "Em torno de 1970, coisas estranhas começaram a acontecer na fronteira que divide Estados Unidos e México. Centenas de imigrantes ilegais começaram a relatar que sempre que se encontravam em apuros, um estranho padre mexicano chamado Toribio Romo aparecia de repente e os ajudava a cruzar a fronteira, até mesmo lhes dando comida, água, dinheiro e informações em como conseguir empregos nos Estados Unidos. Às vezes, ele se aproximava dos ilegais em sofrimento pelo calor, exaustão, mordidas de cobra e outras enfermidades, e os curava. Os imigrantes pensavam se tratar de um ser humano real, e não um anjo da guarda". Conforme texto publicado em um pequeno pôster, parte da divulgação do projeto Brinco do inSite_05. 


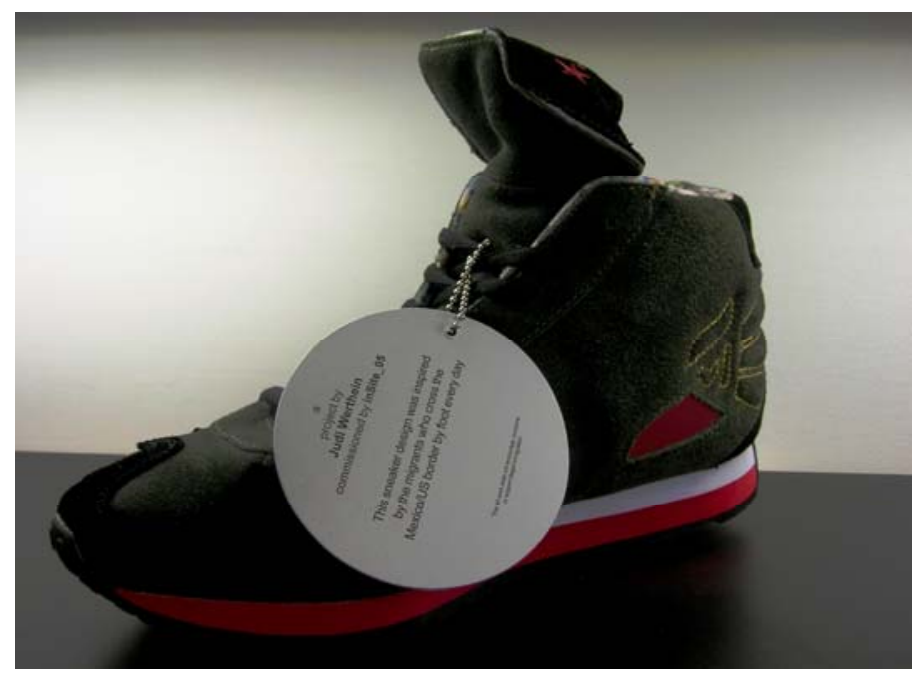

Judi Werthein
Brinco, 2005.
Exposição na loja Blends, Downtown San Diego
Foto do autor

Fabricado em uma maquiladora chinesa, através de um processo de produção que expõe a exploração da mão-de-obra em escala planetária, o tênis foi vendido como "art object" em uma loja de calçados em Downtown San Diego durante a realização da mostra inSite_05, pretendendo enfatizar "as contradições entre moda, competição na indústria e fluxos migratórios, temas centrais da dinâmica da geografia das forças de trabalho no mundo contemporâneo", conforme trecho extraídos da brochura do projeto.

Consumo, moda, exploração pelos países do norte, fluxos migratórios vindo do sul esses são alguns dos elementos que compõem o complexo elenco de questões suscitadas pelo projeto de Judi Werthein - artista argentina (Buenos Aires, 1967) radicada em Nova York - para o inSite_05, tendo como questão central os dramas da fronteira que "saltam aos olhos" e que "a artista não conseguiu evitar", exposta à dor e ao desespero daqueles que acreditam em uma vida melhor no país do norte:

No início, pensei em trabalhar com um tipo de anedotário, mas percebi que não poderia evitar essa questão [da fronteira]. Eu decidi conversar com os migrantes... eu estava aqui [na região] e isso aqui é uma questão de grande interesse. Embora pudesse ter me envolvido com outras situações, entendi que tinha a responsabilidade de não evitar esse assunto, tinha que confrontá-lo com o meu projeto. Ele estava constantemente saltando diante dos meus olhos... No fundo, o que realmente me interessava era aquilo, independentemente se gostasse ou não, foi o que senti que precisava falar 
aqui. Então busquei uma estratégia para intervir nesta estrutura de conflitos políticos, sociais e urbanos.

[...] Comecei com os migrantes, falando com eles, passando um tempo com eles, entrevistando-os... Foi tudo muito triste, uma história triste, foi realmente difícil, não foi uma experiência prazerosa. Percebi que não tinha escolhido algo agradável; certamente poderia ter feito algo diferente... Mas isso não aconteceu comigo, e fui exposta a toda aquela dor, todas aquelas pessoas diante de mim, e aquele era o material bruto que tinha para trabalhar... Como poderia comunicar aquele desespero, aquela desigualdade? Pessoas que perderam sua dignidade... Pessoas que estão se mudando para os Estados Unidos por uma vida melhor. Para mim foi algo que realmente não pude evitar.

As questões que envolvem o processo de mobilidade e trânsito na fronteira que divide os Estados Unidos e a América Latina, seu controle, restrições e dramas, são certamente complexas; no entanto, não são os únicos problemas suscitados pelo projeto Brinco. Ao lado do consumismo em escala planetária, que encontra sua melhor expressão na cultura norte-americana, com sua capacidade de encolher o mundo na procura do melhor custo de mão de obra para a indústria, onde quer que ela esteja, no vizinho México ou na distante China, o projeto de Judi Werthein também propicia reflexões interessantes no campo da arte.

A primeira questão é aquela que investiga a localização mais precisa da obra de Judi Werthein: estaria no processo de desenvolvimento do projeto em si, que incluiu as pesquisas e a colaboração com os migrantes, as organizações de apoio e a própria indústria chinesa? Ou estaria na travessia dos migrantes em direção aos Estados Unidos, calçando o par de tênis em questão? Ou ainda em sua configuração mais convencional como objeto-múltiplo-de-arte ${ }^{13}$, em exposição e venda na loja de calçados Blends, em San Diego, enquanto parecia ampliar o circuito de arte da cidade?

Seja qual for a resposta a essas indagações, até porque Brinco parece ser tudo isso, realizando-se justamente na confluência dessas questões e contradições, o projeto de Judi Werthein parece ainda atender, mesmo que lateralmente, ao anseio

\footnotetext{
${ }^{13} \mathrm{O}$ projeto Brinco produziu 1.000 pares do tênis, dos quais 600 foram destinados à distribuição entre os migrantes, através de organizações com atuação na área, enquanto os outros 400 foram postos à venda por US\$215 na loja Blends, de San Diego, na condição de um múltiplo de arte.
} 
colecionista dos patronos do inSITE, no qual coleções de arte contemporânea têm sido formadas em decorrência de um contato direto e privilegiado com artistas internacionais em sua permanência em San Diego.

Por outro lado, se encontramos dificuldade para precisar o lugar de Brinco, seguramente mais problemas teríamos para identificar seu público. Afinal, seria o imigrante, copartícipe do projeto, a quem (em tese) o projeto estaria servindo? Aquele "público secundário" que visitou a loja Blends na noite de lançamento do projeto? O consumidor que teve seu caminho cruzado pelo par de tênis enquanto buscava um calçado na loja? Ou aquele público que no futuro provavelmente irá confrontar um par de tênis Brinco em um espaço tradicional do sistema de arte? Ou ainda aquele que tomará conhecimento do projeto através das páginas da história da arte?

Curiosamente, apesar de sua extraordinária multiplicidade em 1.000 pares, dois mil objetos, o projeto Brinco parece destinado à invisibilidade, já que o calçado em si não é mais do que uma referência simbólica aos dramas da travessia e ao projeto da artista, sendo a um só tempo, sua realidade e sua metáfora.

De qualquer maneira, como se não bastassem as complexidades centrais que moveram a artista ao se decidir por lidar com os problemas da fronteira, Brinco ainda incorporou outras questões certamente relevantes, que poderiam, por um lado, adensar a complexidade do projeto, mas que também puseram o projeto sob o risco da pulverização, da dispersão e desfocalização.

\section{REFERÊNCIAS}

DOHERTY, Claire. The New Situationists. In: DOHERTY, Claire (ed.). Contemporary Art: From Studio to Situation. Londres: Black Dog Publishing, 2004, p. 7-13.

FIRSTENBERG, Lauri. San Diego-Tijuana. Art Papers Magazine, Atlanta, Georgia, v. 29, n. 6, p. 60, nov. - dez. 2005.

FOUCAULT, Michel. Of Other Spaces. Diacritics 16, primavera de 1986, p. 22-27.

FRASER, Andrea. Museum Highlights: the Writings of Andrea Fraser. ALBERRO, Alexander (ed.). Cambridge, Mass.: The MIT Press, 2005. 
FUENTES, Carlos. A fronteira de cristal. In: A fronteira de cristal. Trad. Mauro Gama. Rio de Janeiro: Rocco, 1999.

HUNTINGTON, Samuel P. O choque de civilizações e a recomposição da ordem mundial. Trad. M.H.C. Côrtes. Rio de Janeiro: Objetiva, 1996.

HUNTINGTON, Samuel P. The Hispanic Challenge. Foreign Policy, n.141, p. 30-45, mar./abr. 2004.

JACOB, Mary Jane. Outside the Loop. In: JACOB, Mary Jane; BRENSON, Michael; e OLSON, Eva M. Culture in action. Seattle, Wash.: Bay Press, 1995, p. 50-61.

JUSIDMAN, Yishai. inSITE. Art Issues, San Diego, no. 36, jan. - fev. 1995, p. 46-48.

KESTER, Grant H. Conversation Pieces: Community + Communication in Modern Art. Berkeley, Cal.: University of California, 2004.

KRAVAGNA, Christian. Working on the Community: Models of Participatory Practice. Disponível em: <http://www.republicart.net>.

KWON, Miwon. One Place After Another: Site-Specific Art and Locational Identity. Cambridge, Mass.: The MIT Press, 2002.

PAZ, Octavio. Tempo nublado. Rio de Janeiro: Editora Guanabara, 1986.

PHILLIPS, Patricia C. Temporality and Public Art. In: SENIE, Harriet F. e WEBSTER, Sally (eds.). Critical Issues in Public Art. Washington, D.C.: Smithsonian Institution Press, 1998, p. 295-304. 